\title{
Glucagon-Like Peptide-1 Secreting L-Cells Coupled to Sensory Nerves Translate Microbial Signals to the Host Rat Nervous System
}

\author{
Maria M. Buckley 1,2, Rebecca O'Brien ${ }^{1}$, Eilish Brosnan ${ }^{1}$, R. Paul Ross ${ }^{2,3,4}$, \\ Catherine Stanton ${ }^{2,4}$, Julliette M. Buckley ${ }^{5,6}$ and Dervla O'Malley ${ }^{1,2 * t}$ \\ ${ }^{1}$ Department of Physiology, University College Cork, Cork, Ireland, ${ }^{2}$ APC Microbiome Ireland, University College Cork, Cork, \\ Ireland, ${ }^{3}$ College of Science, Engineering and Food Science, University College Cork, Cork, Ireland, ${ }^{4}$ Teagasc Food Research \\ Centre, Cork, Ireland, ${ }^{5}$ Department of Surgery, University College Cork, Cork, Ireland, ${ }^{6}$ Mater Private Hospital, Cork, Ireland
}

\section{OPEN ACCESS}

Edited by:

Andrew L. Gundlach, University of Melbourne, Australia

Reviewed by: John Bienenstock, McMaster University, Canada Richard L. Young,

University of Adelaide, Australia

*Correspondence: Dervla O'Malley d.omalley@ucc.ie

TORCID:

Dervla O'Malley orcid.org/0000-0002-7031-4879

Specialty section:

This article was submitted to Cellular Neurophysiology, a section of the journal Frontiers in Cellular

Neuroscience

Received: 14 February 2020 Accepted: 30 March 2020 Published: 30 April 2020

Citation:

Buckley MM, O'Brien R, Brosnan E, Ross RP, Stanton C, Buckley JM and O'Malley D (2020) Glucagon-Like Peptide-1 Secreting L-Cells Coupled to Sensory Nerves Translate Microbial Signals to the Host Rat

Nervous System.

Front. Cell. Neurosci. 14:95. doi: 10.3389/fncel.2020.00095
An intact gut epithelium preserves the immunological exclusion of "non-self" entities in the external environment of the gut lumen. Nonetheless, information flows continuously across this interface, with the host immune, endocrine, and neural systems all involved in monitoring the luminal environment of the gut. Both pathogenic and commensal gastrointestinal (Gl) bacteria can modulate centrally-regulated behaviors and brain neurochemistry and, although the vagus nerve has been implicated in the microbiota-gut-brain signaling axis, the cellular and molecular machinery that facilitates this communication is unclear. Studies were carried out in healthy Sprague-Dawley rats to understand cross-barrier communication in the absence of disease. A novel colonic-nerve electrophysiological technique was used to examine gut-to-brain vagal signaling by bacterial products. Calcium imaging and immunofluorescent labeling were used to explore the activation of colonic submucosal neurons by bacterial products. The findings demonstrate that the neuromodulatory molecule, glucagon-like peptide1 (GLP-1), secreted by colonic enteroendocrine L-cells in response to the bacterial metabolite, indole, stimulated colonic vagal afferent activity. At a local level indole modified the sensitivity of submucosal neurons to GLP-1. These findings elucidate a cellular mechanism by which sensory L-cells act as cross-barrier signal transducers between microbial products in the gut lumen and the host peripheral nervous system.

Keywords: enteric neurons, indole, GLP-1, microbiota, vagus nerve, tryptophan

\section{INTRODUCTION}

The peripheral nervous system innervating the colon has evolved in the continued presence of over a 100 trillion microbial organisms, mostly bacteria. These microbes are predominantly beneficial, scavenging additional calories, secreting vitamins and ensuring normal immune and gastrointestinal (GI) development, but it appears that they may also manipulate host physiology and behavior to their benefit (Stilling et al., 2016). Alterations in the luminal microbiota have been linked with stress-related disorders, Parkinson's disease, autism spectrum disorder and schizophrenia (Dinan and Cryan, 2013, 2017). The vagus nerve has been implicated in the 


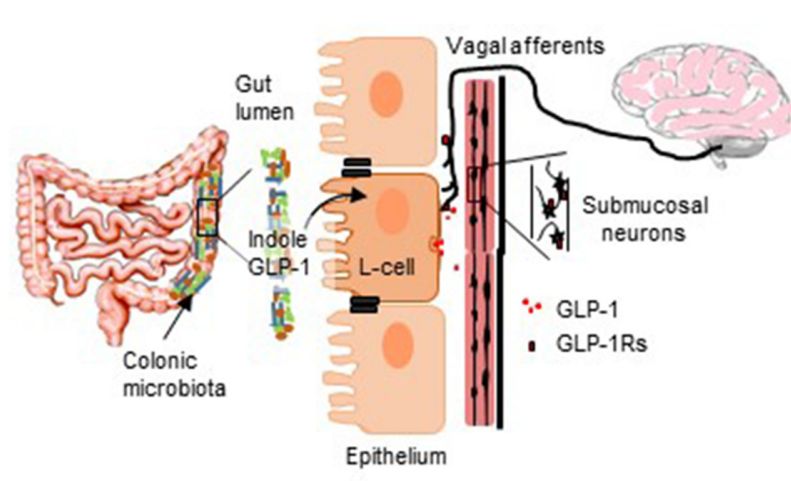

GRAPHICAL ABSTRACT | The diagram illustrates the proposed role of GLP-1-secreting L-cells in translating bacterially-originating signals to neurostimulatory actions.

modulation of host behavior and altered central expression of neurotransmitters by putative probiotics (Bercik et al., 2011; Bravo et al., 2011; Perez-Burgos et al., 2013). Indeed, stimulation of vagal nerve activity (Perez-Burgos et al., 2013) and activation of intrinsic primary afferent neurons (Mao et al., 2013) in response to the exposure of mouse jejunum mucosa to Lactobacillus Rhamnosus JB-1 have been reported. Intrinsic primary afferent neurons may act as a neural starting point of gut-to-brain signaling (Perez-Burgos et al., 2014) and indeed, are less excitable in the absence of gut microbes (McVey Neufeld et al., 2013). However, a mechanistic understanding of how these bacterial signals are interpreted by the host is yet to be established.

Bacteria can infiltrate the gut (Pérez-Berezo et al., 2017; Jaglin et al., 2018) and, this is indeed more likely in disorders associated with increased GI permeability, such as Irritable Bowel Syndrome (IBS). However, given that the healthy gut is immunologically primed to detect and prevent bacterial penetration, it is likely that an integral homeostatic signaling mechanism, which maintains the integrity of the gut barrier, exists to facilitate microbiota-gut-brain signaling. Pathogen associated molecular patterns, which identify and evoke a host response to pathogenic microbes, are well described in the gut epithelium, and Nod-like receptors are implicated in gut-brain signaling (Pusceddu et al., 2019), however, other cells in the epithelium act as chemosensory transducers for non-threating gut stimuli. Serotonin biosynthesis was stimulated by chemical irritants, volatile fatty acid fermentation products and catecholamines (Yano et al., 2015), which subsequently modulated primary afferent nerve fibers via synaptic connections (Bellono et al., 2017). Thus, enterochromaffin cells transduce environmental, metabolic, and homeostatic information from the gut lumen to the nervous system. However, L-cells also act as biosensors of the gut lumen.

Electrically-excitable enteroendocrine L-cells are embedded in the epithelium and secrete glucagon-like peptide-1 (GLP-1) from their basolateral face following stimulation (Chimerel et al., 2014). L-cells are found throughout the small and large intestine (Hansen et al., 2013), but function differently depending on their location. For instance, small intestinal L-cells in humans
(Sun et al., 2017) and rats (Kuhre et al., 2015) are sensitive to glucose, whereas in vitro colonic L-cells express bile receptors and receptors for short-chain fatty acids (Tolhurst et al., 2012). Bacterial metabolites such as indole (Chimerel et al., 2014), S-equol (Harada et al., 2018) and prebiotics (Gibson and Roberfroid, 1995; Cani et al., 2006) induce GLP-1 secretion, but conversely, GLP-1 is also elevated in germ-free mice (Wichmann et al., 2013). Although L-cells are classically described as endocrine cells, like enterochromaffin cells (Bellono et al., 2017), they can synapse directly with peripheral afferent and efferent neurons (Bohórquez et al., 2015), providing a direct neural pathway for bi-directional brain-gut communication (Kaelberer et al., 2018). Despite growing interest in the microbiota-gutbrain axis, relatively little is known about the chemosensory transduction of microbial signals across an intact barrier. In this study, we have investigated the capacity of L-cells to interpret bacterial signals from the gut lumen and activate host colonic afferents and intrinsic neurons by secreting GLP-1.

\section{MATERIALS AND METHODS}

\section{Ethical Approval}

All animal experiments were in full accordance with the European Community Council Directive (86/609/EEC) and the local University College Cork Animal Experimentation Ethics Committee. Rats were sacrificed by $\mathrm{CO}_{2}$ overdose and perforation of the diaphragm.

\section{Animals and Tissue Collecting}

Sprague-Dawley rats were used to determine if bacterial products could activate enteric neurons and the vagus nerve across an intact, non-leaky colon (Gareau et al., 2007). Male Sprague-Dawley rats (8-12 weeks) purchased from Envigo, Derbyshire, UK, were group-housed five per cage and maintained on a $12 / 12 \mathrm{~h}$ dark-light cycle (08.00-20.00) with a room temperature of $22 \pm 1^{\circ} \mathrm{C}$. Animals were permitted at least 1 week to acclimatize to their new environment before experimentation. Standard chow diet and water were available ad libitum. A section of colon $8 \mathrm{~cm}$ proximal to the anus was excised from each rat and maintained in ice-cold Krebs saline containing in mM/L: $117 \mathrm{NaCl}, 4.8 \mathrm{KCl}, 2.5 \mathrm{CaCl}_{2}, 1.2 \mathrm{MgCl}_{2}$, $25 \mathrm{NaHCO}_{3}, 1.2 \mathrm{NaH}_{2} \mathrm{PO}_{4}$ and 11 D-glucose (pH 7.4).

\section{Commensal Bacterial Strains}

Lactobacillus paracasei NFBC 338 (L.paracasei) was transformed to secrete a long-acting analog of GLP-1, confirmed by mass spectrometry and in vitro assays of insulinotropic activity (Ryan et al., 2017). The engineered commensal bacteria were cultured at $1 \%(\mathrm{v} / \mathrm{v})$ in de Man, Rogosa and Sharpe broth (Difco, VWR, Philadelphia, PA, USA) for $\sim 17 \mathrm{~h}$ at $37^{\circ} \mathrm{C}$ under anerobic conditions [anerobic jars with Anaerocult A Gas Packs (Merck, Darmstadt, Germany)] until stationary phase and centrifuged $\left(16,900 \times g\right.$ for $15 \mathrm{~min}$, at $4^{\circ} \mathrm{C}$; SLA-3000 rotor, Sorvall RC B5Plus). The cell pellet was washed twice with phosphate-buffered saline (PBS; Sigma Aldrich, UK), re-suspended at $\sim 2 \times 10^{10}$ CFU.ml ${ }^{-1}$ in sterile $15 \%$ trehalose (Sigma Aldrich), which acted as a cryoprotectant and $1 \mathrm{ml}$ aliquots were dispensed into $2 \mathrm{ml}$ 
lyophilization vials. The vials were lyophilized on a $24 \mathrm{~h}$ program (freeze temperature $-40^{\circ} \mathrm{C}$, additional freeze $1 \mathrm{~min}$, condenser set point -60 , vacuum setpoint 600 mTorr; VirTis AdVantage Wizard 2.0) and stored at $4{ }^{\circ} \mathrm{C}$. Bacteria were resuspended in distilled water each day to deliver $1 \times 10^{10}$ CFU.ml ${ }^{-1}$ for each exposure.

\section{Colonic-Afferent Nerve Electrophysiological Recordings}

The detailed description of the ex vivo dissection technique and recording of distal colonic afferent nerves has been previously reported (Buckley and O'Malley, 2018). In brief, a segment of the esophagus with the attached posterior vagus nerve was excised from an adult Sprague-Dawley rat. Maintaining an intact neural connection to the esophagus, a segment of distal colon $(5 \mathrm{~cm}$ from the anus) with attached inferior and superior mesenteric ganglia, celiac ganglia and vagus nerve were placed in a recording chamber. Adjacent Sylgard-lined chambers allowed the afferent nerves to be isolated from the distal colon. The colon was opened, mucosal side up and the vagus nerve was carefully threaded through to the adjacent chamber and the gap was sealed with petroleum jelly (Figure 1B). Both chambers were superfused with $5 \% \mathrm{CO}_{2} / 95 \% \mathrm{O}_{2}$ bubbled Krebs-buffered saline maintained at $37^{\circ} \mathrm{C}$. Multi-unit neural activity was recorded using platinum bipolar recording electrodes (WPI, Sarasota, FL, USA) attached to a Power lab (AD Instruments, Oxford, UK). Reagents [indole (1 mM, Sigma-Aldrich: cat. No. I3408), exendin 3(9-39) amide (10 $\mu \mathrm{M}$, Tocris; cat. No. 2081), exendin-4 (10 $\mu \mathrm{M}$, Tocris: cat. No. 1933) or tetrodotoxin (10 nM, Tocris: cat. No. 1078)] were applied to the colonic bath in the superfusate. Nerve activity was viewed and analyzed with Chart 7 (AD Instruments, Oxford, UK). Changes in multi-unit neural activity in the vagal nerve are presented as frequency from raw traces. Both raw and rectified traces are presented.

\section{Immunofluorescence and Confocal Microscopy}

Whole-mount colonic submucosal plexus (SMP) preparations were pinned out in Sylgard-lined dishes and fixed in $4 \%$ paraformaldehyde $\left(4^{\circ} \mathrm{C}\right.$, overnight). The tissues were subsequently permeabilized with $0.1 \%$ Triton X-100 and blocked with $1 \%$ donkey serum (Sigma Aldrich). SMP tissue was incubated with primary antibodies (1:250@ $4^{\circ} \mathrm{C}$ overnight) against GLP-1 [rabbit polyclonal antibody (ab22625), Abcam, Cambridge, UK (Duca et al., 2013)] or goat polyclonal antibody (sc7782; Santa Cruz Biotechnology Inc, TX, USA), GLP-1 receptors [GLP-1R, mouse polyclonal antibody (sc66911), Santa Cruz Biotechnology] and FITC-conjugated anti-rabbit or anti-goat and TRITC-conjugated anti-rabbit or anti-mouse secondary antibodies (1:250, $2 \mathrm{~h}$ at room temperature, Jackson Immunoresearch, Westgrove, PA, USA). Images were captured using an FVl0i-Olympus-confocal microscope with Fluoview software (FV10i-SW). No non-specific fluorescence was detected in control experiments where tissues were incubated with primary antibodies or secondary antibodies alone, or where anti-GLP-1R antibodies were neutralized with a blocking peptide before the staining protocol. Changes in the optical density of GLP-1R expression was quantified using Image (National Institute of Health, USA). Membrane expression of GLP-1Rs from three neurons per ganglia in three different tissue preparations were compared when indole was applied to the submucosal neurons or the mucosa.

\section{Calcium Imaging}

For calcium imaging studies, whole-mount preparations of SMP neurons were prepared from the distal colon of healthy Sprague-Dawley rats. The colon was mounted on a glass rod, where the outer serosal layer was scored lightly with a blade along the mesenteric border. To prepare an SMP tissue preparation, the serosal and mucosal layers were removed and the colonic tissue $(\sim 2 \mathrm{~cm} \times 2 \mathrm{~cm})$ was pinned out in Sylgardlined dishes. Submucosal neuronal preparations were loaded with Fura-2AM (7 $\mu \mathrm{M}, 1 \mathrm{~h}$, Thermo-Fisher Scientific, UK) or Fluo-8 $(8 \mu \mathrm{M}, 1 \mathrm{~h}, \mathrm{Abcam}, \mathrm{UK})$ in Krebs-buffered saline solution comprised of (in $\mathrm{mM} \mathrm{l}^{-1}$ ): $\mathrm{NaCl}, 117 ; \mathrm{KCl}, 4.8 ; \mathrm{CaCl}_{2}$, 2.5; $\mathrm{MgCl}_{2}, 1.2 ; \mathrm{NaHCO}_{3}, 25 ; \mathrm{NaH}_{2} \mathrm{PO}_{4}, 1.2$ and D-glucose, 11 ; prior to imaging. SMP tissue preparations were used to investigate the activation of submucosal neurons in the absence of epithelial and enteroendocrine cells and their secretions. A hemisected colonic tissue preparation (Mao et al., 2013), where the SMP is exposed on one half of the tissue but the mucosa is left intact on the other half (Figure 3E), was used to compare calcium responses evoked by neuronal exposure to Ex-4 before and after mucosal application of indole. The presence of the epithelium indicates that mucosally-secreted factors are implicated in the modification of neuronal function. Reagents [indole $(1 \mathrm{mM})$, exendin-4 $(10 \mu \mathrm{M})$, exendin 3(9-39) amide $(10 \mu \mathrm{M})$, thapsigargin (100 nM, Tocris: cat. No. 1138), $\omega$-agatoxin IVA (100 nM, Sigma Aldrich: cat. No. A6719), $\omega$-conotoxin GVIA (100 nM, Sigma Aldrich: cat. No. C9915), wortmannin (100 nM, Sigma Aldrich: cat. No. W1628), WP1006 (1 $\mu \mathrm{M}$, Calbiochem) and PD98059 (1 $\mu \mathrm{M}$, Sigma Aldrich: cat. No. 513000)] were added to the perfusate. Images were acquired at $1 \mathrm{~Hz}$ using a conventional fluorescence imaging system (Cairn Life technologies, UK or Olympus, Melville, NY, USA), and a water-immersion objective (Olympus, $40 \times$ magnification, numerical aperture: 0.80 ) on a fixed stage upright microscope (Olympus BX51WI). Cell R software (Olympus Soft imaging solutions, Munster, Germany) or WinFluor Fluorescence Image Capture and Analysis program (John Dempster, University of Strathclyde, Scotland) was used to record excitation changes in intracellular calcium (O’Malley et al., 2011b).

As previously described (O'Malley et al., 2011a), submucosal neurons were identified based on morphology and responsivity to brief application of $75 \mathrm{mM} \mathrm{KCl}$ at the end of the recording protocol. Reagents were applied in a random order to avoid the run-down of calcium stores being a confounding factor. The colonic tissue was continuously superfused with carbogenbubbled Krebs-buffered saline at room temperature containing the L-type calcium channel blocker, nifedipine (1 $\mu \mathrm{M}$, SigmaAldrich, cat. No.: N7634), to inhibit smooth muscle contraction. Responding neurons were defined as those which exhibited an increase in intracellular calcium $\left(\left[\mathrm{Ca}^{2+}\right]_{i}\right)$ that was greater than two standard deviations from the baseline values in that cell 
A
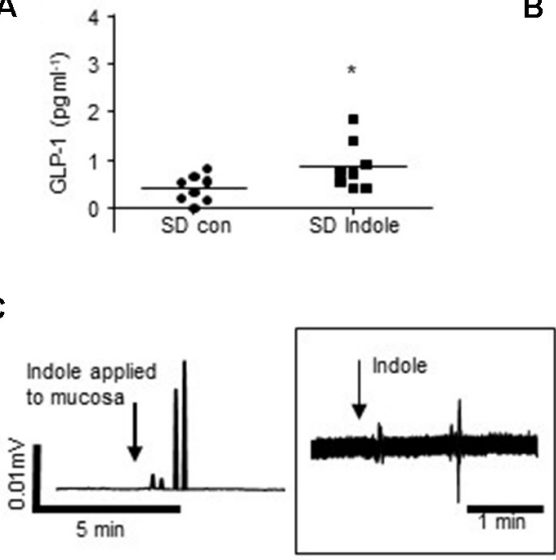

B
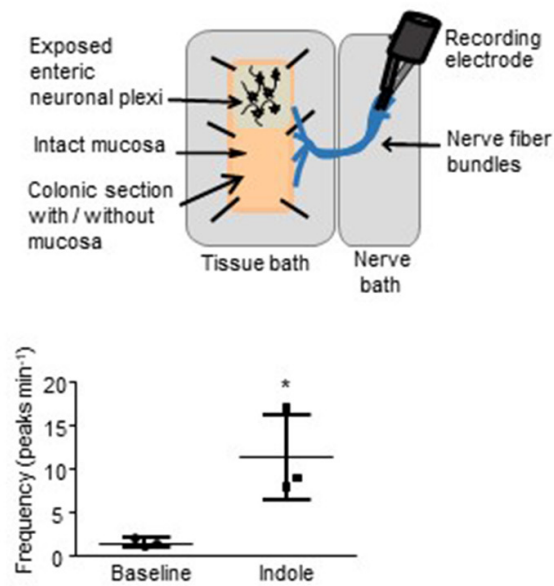

D

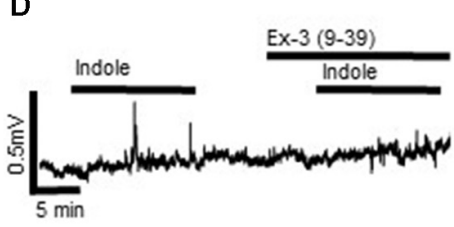

E

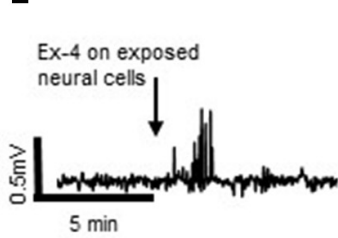

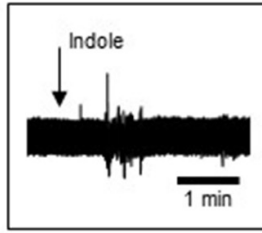
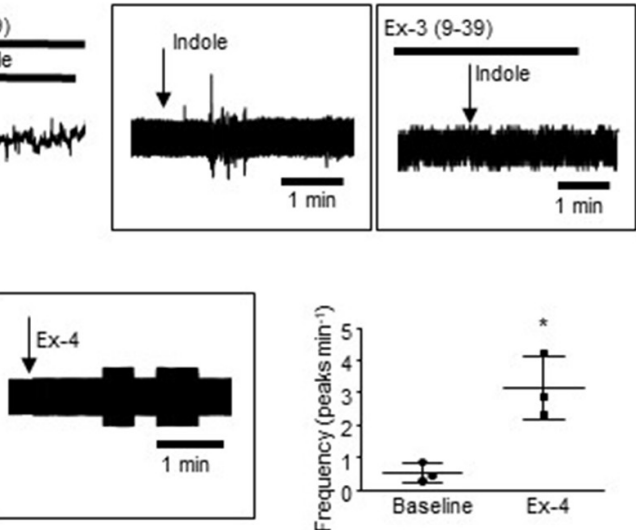

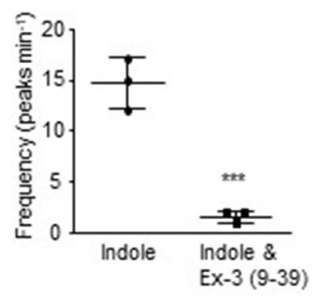

$\mathbf{F}$
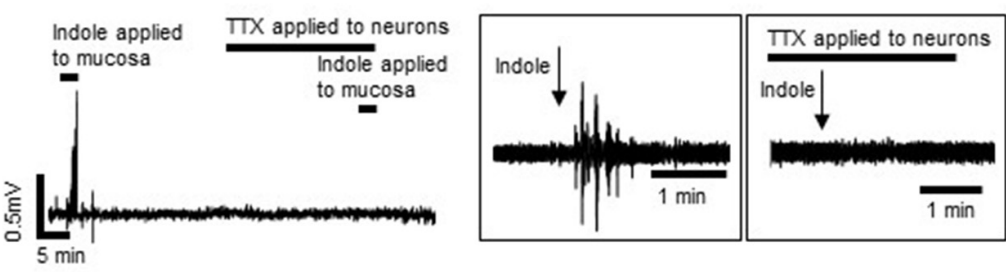

G
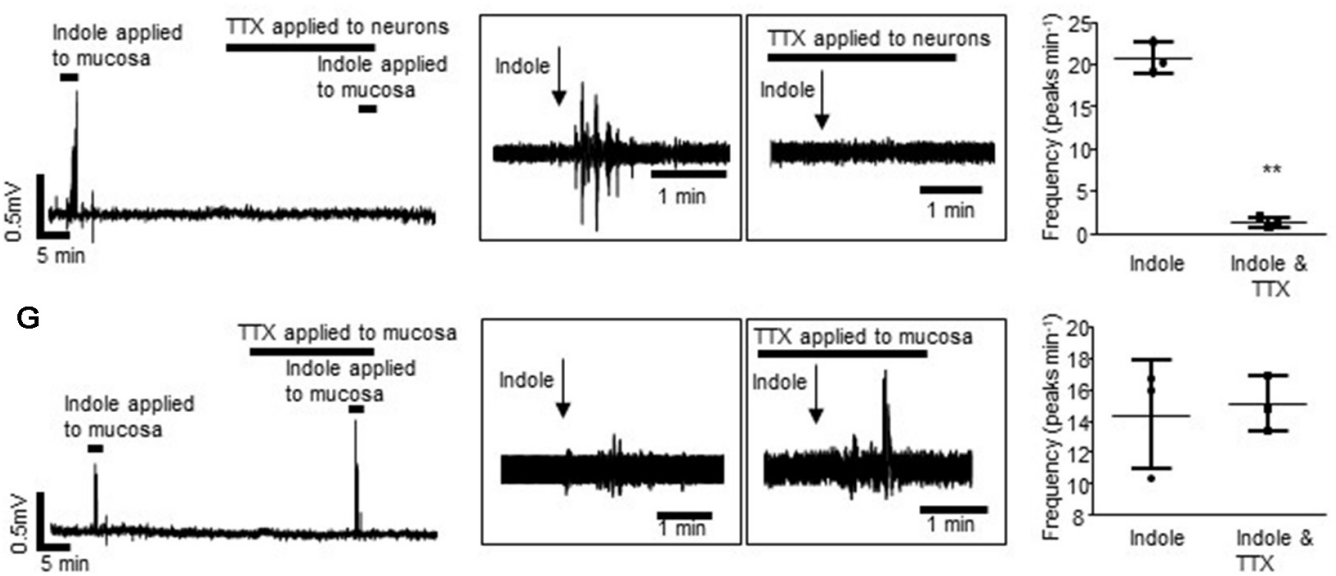

FIGURE 1 | L-cells facilitate indole-evoked activation of vagal afferents. (A) The plot illustrates basolateral secretion of Glucagon-like peptide-1 (GLP-1) from colonic tissue apically exposed to indole (1 mM, $30 \mathrm{~min}$ ) or saline (control). (B) The schematic (amended from Buckley and O'Malley, 2018) illustrates the ex vivo distal colonic tissue preparation. Recording is made from vagal afferents attached to the esophagus. The mucosa can be left intact, or removed to expose enteric neurons and associated afferent endings. (C) The rectified and raw (in boxes) traces show vagal nerve activity in response to stimulation of the distal colonic mucosa. Scatter plots illustrate peak frequency. Indole-evoked vagal nerve activity was attenuated by (D) exendin 3(9-39) amide [Ex-3(9-39)]. (E) Exendin-4 (Ex-4) stimulated vagal nerve firing when applied to the exposed neurons. (F) Tetrodotoxin (TTX) inhibited the indole-evoked response when it is applied to a hemisected piece of colonic tissue but not (G) colonic tissue with an intact mucosa. ${ }^{\star} p<0.05,{ }^{\star \star} p<0.01,{ }^{\star \star \star} p<0.001$.

(calculated during the $150 \mathrm{~s}$ preceding stimulus application). Paired analysis of responses within a single neuron were compared to determine the effect of the pharmacological reagent on the control response. 
A
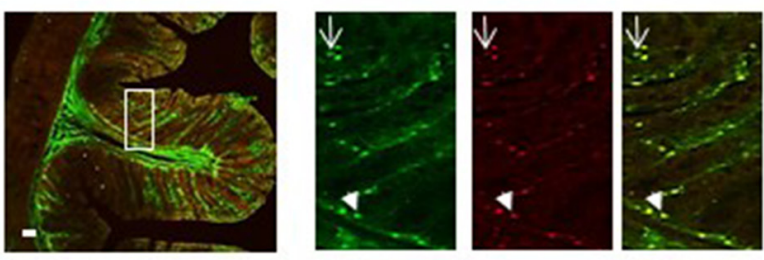

\section{GLP-1}

GLP-1R

B
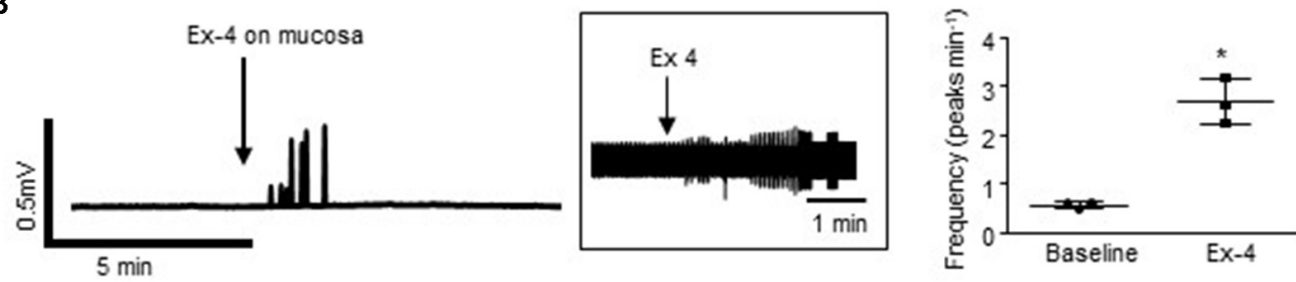

C
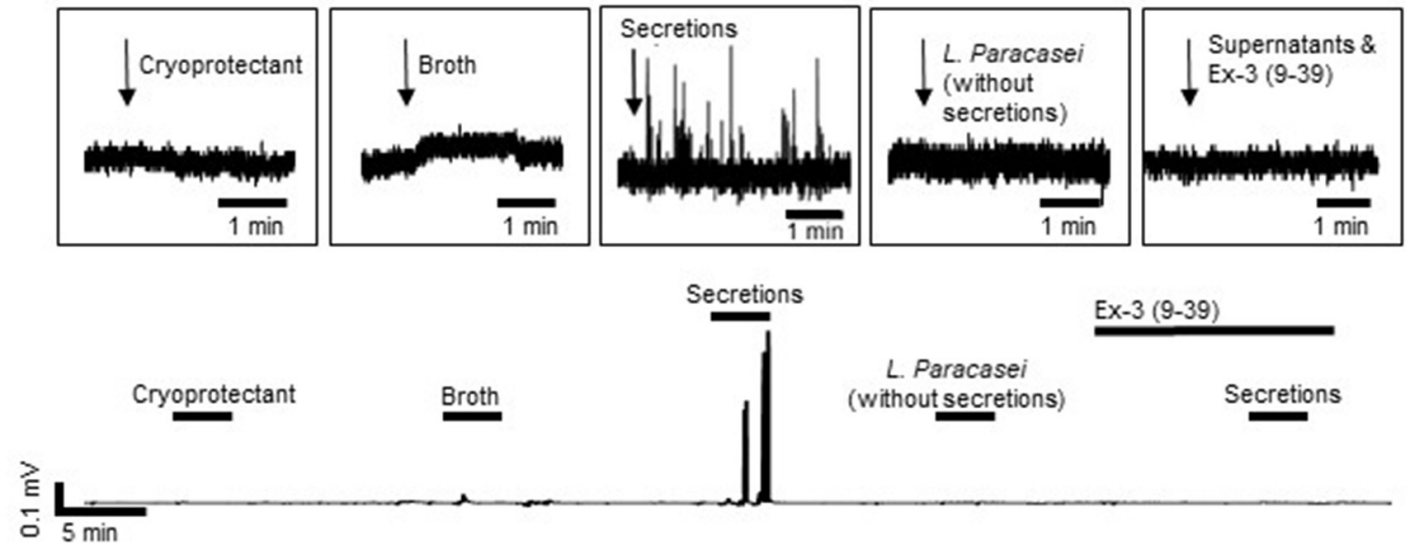

L. Paracasei (without secretions)

Ex-3 (9-39)
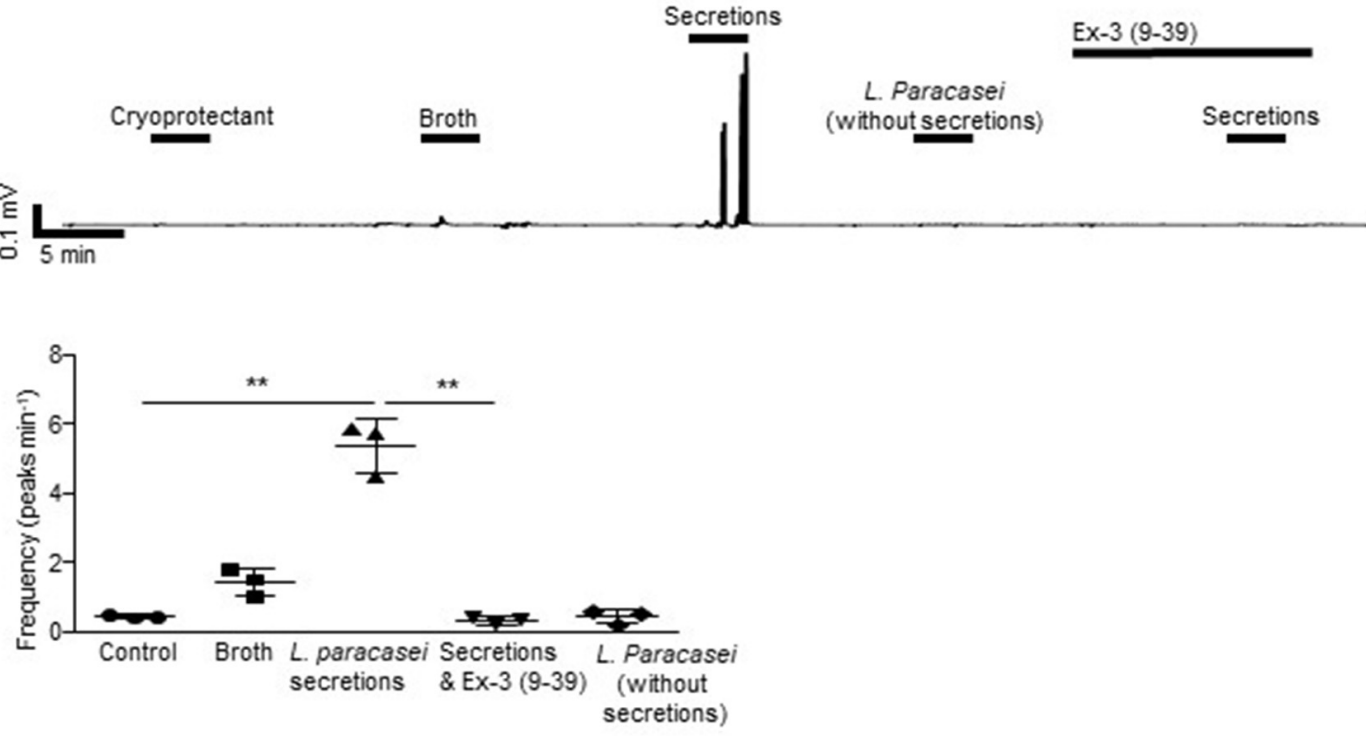

FIGURE 2 | Lactobacillus paracasei secretions stimulate host neurons. (A) The representative immunofluorescent image of a rat colonic cross-section illustrates that some L-cells expressed GLP-1Rs (arrowhead) but others did not (arrow). (B) Mucosal application of exendin-4 (Ex-4) increased vagal activity. (C) Increased vagal nerve activity evoked by $L$. paracasei secretions was abolished by Ex-3(9-39). ${ }^{*} p<0.05,{ }^{* *} p<0.01$. Scale bars: $50 \mu \mathrm{m}$.

\section{Ussing Chamber Electrophysiology}

Mucosa-submucosal preparations of distal colon were mounted in Ussing chambers (exposed area of $0.12 \mathrm{~cm}^{2}$ ) with $5 \mathrm{mls}$ of Krebs saline solution $\left(95 \% \mathrm{O}_{2} / 5 \% \mathrm{CO}_{2}, 37^{\circ} \mathrm{C}\right)$ in the basolateral and luminal reservoirs. Tissues were voltage-clamped at $0 \mathrm{mV}$ using an automatic voltage clamp (EVC 4000, World Precision Instruments, Sarasota, FL, USA) and the short-circuit current
$\left(\mathrm{I}_{\mathrm{SC}}\right)$ required to maintain the $0 \mathrm{mV}$ potential was monitored as a recording of the net active ion transport across the epithelium. Experiments were carried out simultaneously in all chambers and connected to a PC equipped with DataTrax II software (WPI). This software was used to measure the peak response and resistance was calculated using Ohms law. Following mounting, tissue was allowed to equilibrate $(\sim 1 \mathrm{~h})$. Reagents [exendin 4 
A

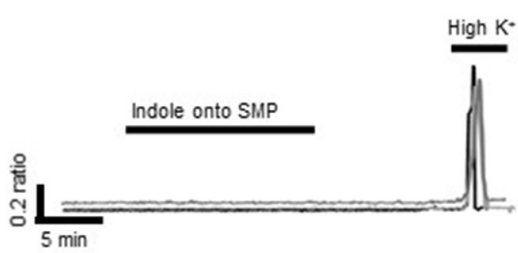

B GLP-1R expression in submucosal ganglia
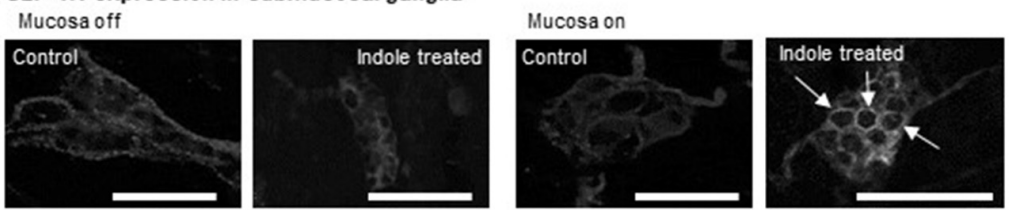

C
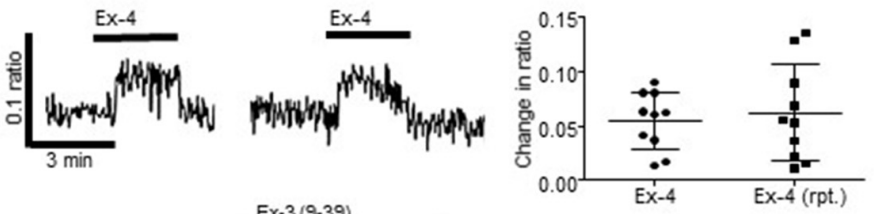

D

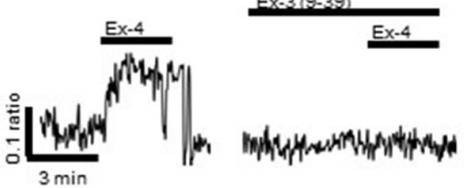

E

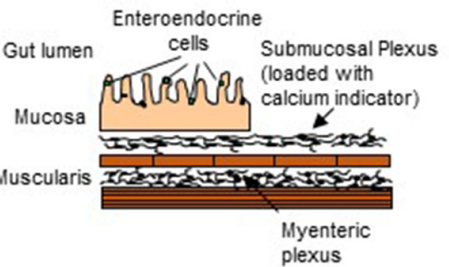

G
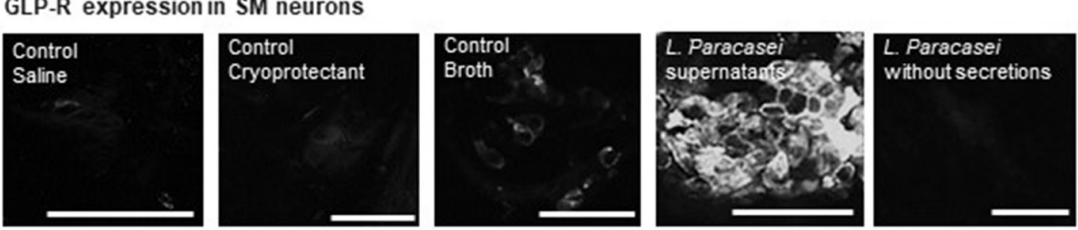

H
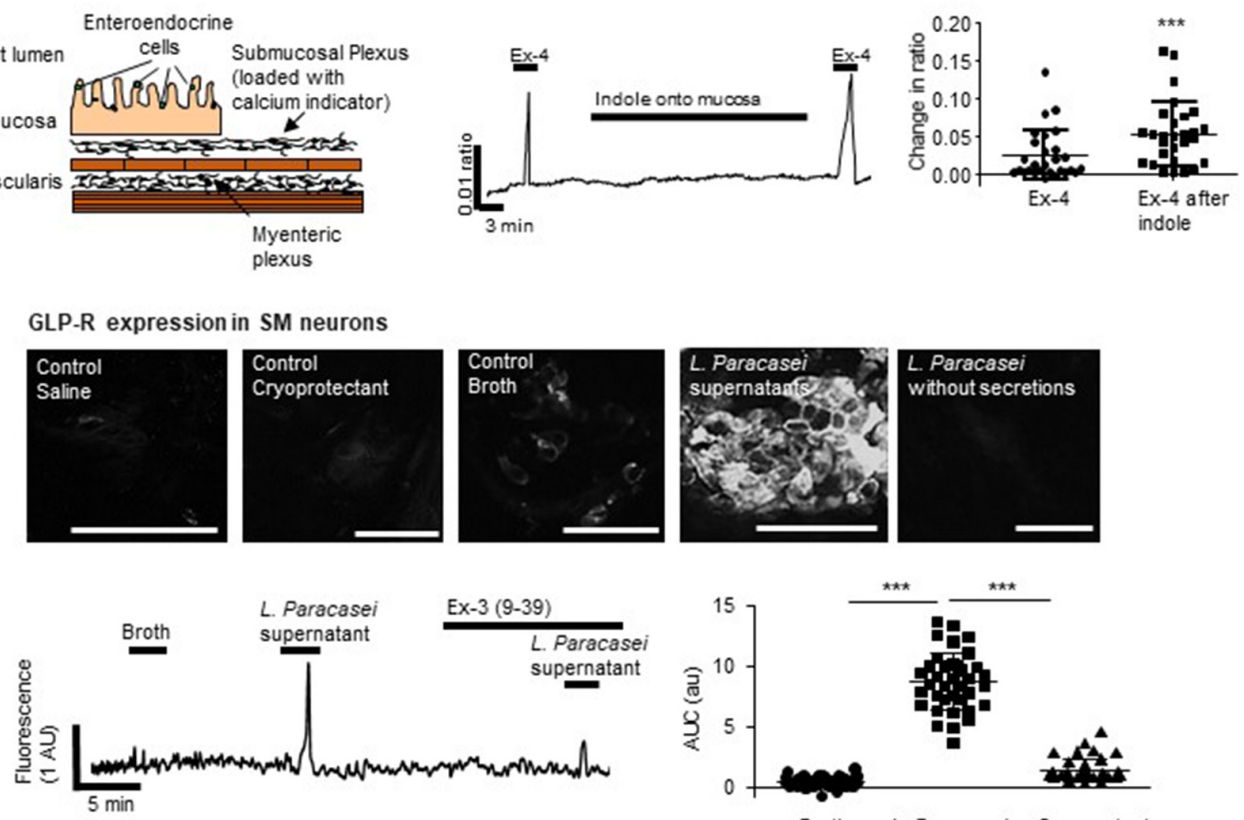

$\mathbf{F}$

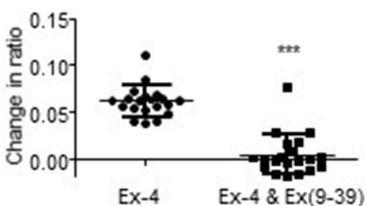

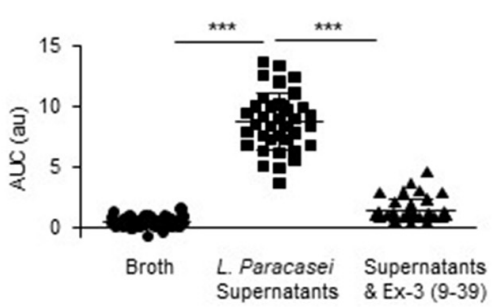

FIGURE 3 | Mucosal L-cells facilitate indole-evoked activation of submucosal neurons. (A) Indole did not affect intracellular calcium ([Ca $\left.\left.{ }^{2+}\right]_{i}\right)$ levels in submucosal neurons. (B) Immunofluorescence images show the GLP-1 receptor (GLP-1R) expression in colonic submucosal neurons following neuronal and mucosal exposure to indole. Arrows indicate increased expression at the neuronal cell membranes. Scalebar: $50 \mu \mathrm{m}$. (C) The GLP-1R agonist, exendin 4 (Ex-4) stimulated an increase in $\left[\mathrm{Ca}^{2+}\right]_{i}$, a reproducible effect that was (D) attenuated by the GLP-1R antagonist, exendin 3(9-39) amide [Ex-3(9-39)]. (E) The schematic illustrates a cross-section of the hemisected distal colon. By removing half of the mucosa, changes in intracellular calcium can be recorded from submucosal neurons loaded with a calcium indicator dye. By leaving some of the mucosa intact, the role of endocrine hormones secreted by epithelial cells can be investigated. (F) In hemisected colonic tissue, the Ex-4-evoked calcium response was enhanced by mucosal indole. (G) Immunofluorescent images show GLP-1R expression in colonic submucosal neurons following mucosal stimulation with saline, cryoprotectant, broth, L. paracasei secretions, and L. paracasei bacteria. Scalebar: $50 \mu \mathrm{m}$. (H) Mucosal application of $L$. paracasei secretions evoked a calcium response in submucosal neurons which was attenuated by the GLP-1R antagonist, exendin 3(9-39) amide [Ex-3(9-39)]. ${ }^{\star \star \star} p<0.001$. 
(10 $\mu \mathrm{M})$, carbachol (10 $\mu \mathrm{M}$, Sigma-Aldrich, cat. No.: Y0000113), veratridine (10 $\mu \mathrm{M}$, Sigma-Aldrich, cat. No.: V5754), capsaicin (1 $\mu \mathrm{M}$, Sigma-Aldrich, cat. No.: M2028)] were added to the basolateral chamber.

Separation of the basolateral and apical surfaces in the Ussing chambers were exploited to determine if basolateral secretion of GLP-1 by colonic L-cells was induced by indole. Distal colonic tissue was mounted in low-volume ( $1 \mathrm{ml}$ carbogenated Krebs saline solution) Ussing chambers with an exposed tissue area of $0.64 \mathrm{~cm}^{2}$. Following mucosal exposure to indole ( $\left.1 \mathrm{mM}, 30 \mathrm{~min}\right)$, secretion of GLP-1 into the basolateral reservoir $(1 \mathrm{ml})$ was ascertained by immunoassay.

\section{Mesoscale Discovery Biomarker Assay}

An immunoassay (MesoScale Discovery U-PLEX customized multiplex assay kit I, MesoScale Discovery, Gaithersburg, MD, USA) with a dynamic range for GLP-1 of $0.02-120 \mathrm{pM}$, was carried out to determine if GLP-1 was secreted in response to indole as compared to saline-treated controls. The assay was run in triplicate and an electrochemiluminescent detection method was used to measure protein levels in each sample. The plates were read using the MesoScale Discovery plate-reader (MESO QuickPlex SQ 120). A calibration curve was generated using standards, and GLP-1 concentrations were determined from the curve.

\section{Statistical Analyses}

Data were analyzed using GraphPad prism for windows (version 5, Graphpad Software, San Diego, CA, USA). The data are represented as data plots with mean \pm the standard deviation. Paired or unpaired $t$-tests or repeated-measures ANOVA with Tukey multiple comparison post hoc test, as appropriate, were used to compare data. $P \leq 0.05$ was considered significant.

\section{RESULTS}

\section{Indole Indirectly Stimulates Activity in Colonic Vagal Afferents}

Sprague-Dawley rats were used to determine if indole, a bacterial metabolite of tryptophan, which stimulates L-cells (Chimerel et al., 2014), can induce cross-barrier signaling in healthy, non-leaky colons (Gareau et al., 2007). In Ussing chamber experiments, exposure of the intact colonic apical epithelial surface to indole $(1 \mathrm{mM}, 30 \mathrm{~min})$ resulted in secretion of GLP-1 into the basolateral reservoir as compared to salinetreated control tissues ( $n=8$ rats, $p=0.0355$, Figure 1A). To investigate if bacterial products may use L-cells to activate the gut-brain neural signaling axis, an ex vivo preparation of rat distal colon with intact colonic afferents was used (Figure 1B; Buckley and O'Malley, 2018). Consistent with previous reports (Richards et al., 1996), baseline afferent activity was low. However, mucosal application of indole stimulated a robust increase in vagal nerve activity ( $n=3$ rats, $p=0.0264$, Figure $1 C$ ). Incubation of the tissue with the GLP-1R antagonist, exendin-3 (9-39) amide [Ex-3 (9-39)], attenuated the indole-evoked response $(n=4, p=0.001$, Figure 1D). Given that GLP-1Rs are expressed in the nodose ganglia (Nakagawa et al., 2004), where cell bodies of afferent vagal neurons are located, basolaterally released GLP-1 could activate vagal afferents. Indeed, direct application of Ex-4 to a tissue preparation with exposed colonic submucosal neurons and afferent nerve endings similarly resulted in increased vagal firing $(n=3, p=0.0219$, Figure 1E), although in the absence of single-unit recordings it is not possible to determine if the same fibers are activated by both indole and Ex-4. In a hemisected colonic tissue preparation (Mao et al., 2013), where submucosal neurons and afferent and efferent nerve endings are exposed, indole-evoked stimulation of vagal nerves was blocked by the neurotoxin, tetrodotoxin $(n=3, p=0.0047$, Figure 1F). Interestingly, in colonic tissue sections where the epithelial layer was left in situ, thereby segregating intrinsic and extrinsic neurons from the luminally-applied tetrodotoxin, indole-evoked vagal stimulation was not inhibited ( $n=3, p=0.6821$, Figure 1G). Thus, action potential generation is crucial for afferent signaling evoked by indole. However, stimulation of neural firing is initiated on the basolateral side of the epithelium. This is consistent with the basolateral secretion of GLP-1 in response to luminal application of indole.

\section{GLP-1 Secreted by L. paracasei Stimulates Colonic Afferents}

Some, but not all GLP-1 immuno-labeled L-cells in the colonic epithelium of $\mathrm{SD}$ rats ( $n=4$ rats, Figure 2A) expressed GLP-1Rs. Thus, GLP-1 originating from sources in the gut lumen could directly or indirectly activate L-cells. Indeed, mucosal application of the GLP-1R agonist, exendin-4 (Ex-4, $10 \mu \mathrm{M})$ increased vagal firing (Figure $2 \mathrm{~B}, n=3, p=0.0124$ ). Although a native GLP-1-secreting microbe has yet to be characterized, a genetically recombineered Lactobacillus paracasei NFBC 338 (L. paracasei), which secretes a long-lasting analog of GLP-1, has been shown to signal across the gut to modify metabolic physiology (Ryan et al., 2017). To demonstrate that luminal application of a bacterial product can modify neural signaling, $L$. paracasei secretions were applied to the mucosa and similarly evoked vagal activation ( $p=0.0074)$, an effect that was abolished by the GLP-1R antagonist, Ex-3 (9-39; $n=4$ rats, $p=0.0095$, Figure 2C). Application of control solutions (bacterial cryoprotectant, culture broth or the probiotics in the absence of their secretory products) did not affect vagal firing.

\section{Indole Indirectly Stimulates Colonic Submucosal Neurons Through the Activation of GLP-1 Receptors (GLP-1Rs)}

Indole can penetrate the gut barrier (Jaglin et al., 2018), however, our studies found that even if this microbial product did cross the epithelium, cytosolic intracellular calcium $\left(\left[\mathrm{Ca}^{2+}\right]_{\mathrm{i}}\right)$ in underlying submucosal neurons, important neural regulators of GI absorpto-secretory function, was unchanged in its presence $(1 \mathrm{mM}, n=32$ neurons from three SMP preparations, Figure 3A). Ganglionic expression of GLP-1Rs, which are most evident in neuronal cell membranes and extra-neuronal cells, was unchanged by direct exposure of submucosal neurons to indole (optical density: $11.3 \pm 1.0$ vs. $10.9 \pm 1.2, n=9$ neurons from three tissue preparations, $p=0.804$, Figure 3B). In contrast, 
application of indole to colonic tissue with an intact epithelium resulted in increased GLP-1R expression (optical density: $7.6 \pm 0.3$ vs. $23.4 \pm 3.3, n=9$ neurons from three tissue preparations, $p=0.0002$, Figure $3 \mathrm{~B}$ ) in submucosal ganglia, which is particularly evident at the cell membranes (indicated by arrows).

To emulate local paracrine actions of basolaterally-secreted GLP-1 on submucosal neurons, a colonic SMP preparation was exposed to Ex-4, a GLP-1 mimetic. Forty-four percentage ( $n=14$ /34 neurons from three SMP preparations) of neurons responded to Ex-4 with a robust, but variable, increase in $\left[\mathrm{Ca}^{2+}\right]_{\mathrm{i}}$. The calcium response was reproducible upon second application ( $n=10$ neurons from three SMP preparations, $p=0.489$, Figure $3 \mathrm{C}$ ) and, consistent with previous studies in myenteric neurons (O'Brien et al., 2019), Ex-3 (9-39) abolished this response $(n=22$ neurons from three SMP preparations, $p<0.0001$, Figure 3D). In hemisected colonic tissue, where half of the mucosa was retained (Figure 3E), the mucosal application of indole did not affect neuronal calcium levels per se (Figure 3F). However, the neuronal calcium response evoked by $\operatorname{Ex}-4 \quad(n=29$ from three SMP preparations, Figure 3 F) was potentiated both in duration and amplitude $(p<0.0001)$ following exposure of the colonic mucosa to indole.

Expression of GLP-1Rs was increased in submucosal neurons following mucosal application of $L$. paracasei secretions but not broth (optical density:14.1 \pm 1.4 vs. $29.5 \pm 2.0, n=9$ neurons from three tissue preparations, $p<0.0001)$. This was primarily at neuronal cell membranes (Figure 3G). Mucosal application of $L$. paracasei secretions to hemisected colonic tissue increased $\left[\mathrm{Ca}^{2+}\right]_{\mathrm{i}}$ in submucosal neurons $(p<0.0001)$, a response that was attenuated by Ex-3(9-39; $n=38$ neurons from three SMP preparations, $p<0.0001$, Figure $3 \mathbf{H}$ ).

\section{Exendin-4 Induces Calcium Influx From Extracellular Sources in Submucosal Neurons}

To understand the cellular mechanisms evoked by activation of neuronal GLP-1Rs after indole-evoked GLP-1 release from colonic L-cells, the neuromodulatory actions of the GLP-1R agonist, Ex-4 (3-min application) was characterized further in the submucosal neurons. Our studies found that the Sarco/endoplasmic reticulum $\mathrm{Ca}^{2+}$ ATPase inhibitor, thapsigargin (100 $\mathrm{nM}, 30 \mathrm{~min})$, reduced but did not abolish calcium responses evoked by $\mathrm{Ex}-4 \quad(n=35$ neurons from three SMP preparations, $p<0.0001$, Figure 4A), implicating calcium release from intracellular stores in submucosal neurons. However, removal of extracellular calcium also attenuated the Ex-4-evoked response ( $n=16$ neurons from three SMP preparations, $p<0.0001$, Figure 4B) indicating the importance of the extracellular influx of calcium. Indeed, the P/Q-channel blocker, $\omega$-agatoxin IVA (100 nM, $30 \mathrm{~min}$, $n=9$ neurons from three SMP preparations, $p=0.032$, Figure 4C), and the N-channel blocker, $\omega$-conotoxin GVIA (100 nM, $30 \mathrm{~min}, n=14$ neurons from three SMP preparations, $p<0.0001$, Figure 4D), attenuated the calcium response

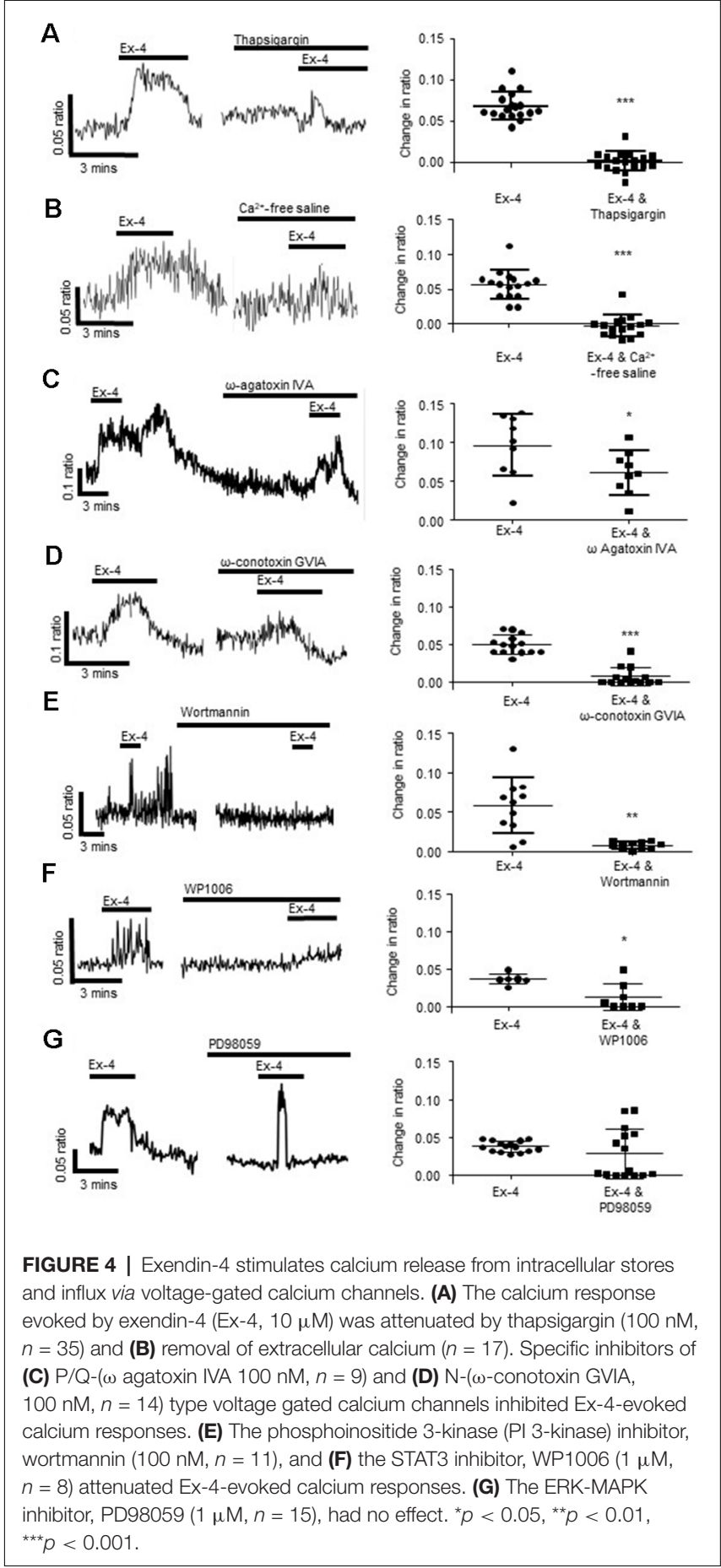

evoked by Ex-4. To inhibit smooth muscle contraction, all calcium imaging studies were carried out in the presence of nifedipine $(1 \mu \mathrm{M})$, an L-type calcium channel blocker, which did not impact on the capacity of Ex-4 to stimulate a calcium response.

Further studies were carried out to understand the intracellular signaling cascades evoked by Ex-4 in submucosal neurons. The Ex-4-evoked calcium response was attenuated by the phosphoinositide 3-kinase (PI 3-kinase) inhibitor, 
wortmannin (100 nM, $30 \mathrm{~min} ; n=11$ neurons from three SMP preparations, $p=0.0013$, Figure $4 E$ ) and the Signal Transducer and Activator of Transcription (STAT)-3 inhibitor, WP1006 ( $1 \mu \mathrm{M}, 30 \mathrm{~min}, n=8$ neurons from three SMP preparations, $p=0.0102$, Figure $4 \mathrm{~F}$ ), while the extracellular-signal-regulated kinase, mitogen-activated protein kinase (ERK-MAPK) inhibitor, PD98059 (1 $\mu \mathrm{M}, 30 \mathrm{~min})$ had no effect on the Ex-4 evoked increase in $\left[\mathrm{Ca}^{2+}\right]_{\mathrm{i}}(n=15$ neurons from three SMP preparations, $p=0.2295$, Figure $4 \mathbf{G})$.

\section{The GLP-1R Agonist, Exendin-4 Modifies Secretory Currents and Gut Permeability}

As Ex-4 modifies the excitability of the SMP and this is the neural regulator of gut absorpto-secretory function, Ussing chambers were used to examine the impact of the GLP-1R agonist on colonic absorpto-secretory currents. As GLP-1 is secreted from the basolateral face of L-cells (Figure 1A), Ex-4 was added to the basolateral chamber of the Ussing chambers. Incubation with Ex-4 resulted in a small secretory current $(n=8$ rats, $p=0.0052$, Figure 5A). Whilst, Ex-4 did not modify secretory currents evoked by the cholinergic agonist, carbachol $(n=6, p=0.0815$, Figure 5B), currents evoked by the $\mathrm{Na}^{+}$channel agonist, veratridine were potentiated $(n=8$, $p=0.0085$, Figure 5C). The afferent nerve stimulant, capsaicin evokes a biphasic secretory and anti-secretory response in colonic tissue. Ex-4 enhanced both the initial secretory phase $(n=6, p=0.0156)$ and the anti-secretory response $(p=0.0462$, Figure 5D). Moreover, the relative change in transepithelial resistance (TER), which is a measure of gut leakiness, throughout the experiment $(60-90 \mathrm{~min})$, increased in tissues continuously exposed to $\operatorname{Ex}-4(n=8, p<0.05)$ compared to the saline-treated control preparations, which showed no change (Figure 5E). This finding suggests that the sustained presence of a GLP-1R agonist reduces colonic permeability.

\section{DISCUSSION}

An intact gut epithelium preserves the immunological exclusion of "non-self" entities in the external environment of the gut lumen. However, despite this physiological defense mechanism, information flows continuously across this interface. Enteroendocrine cells sense stimuli such as nutrients, inflammatory products, irritants, and microbial factors and respond by releasing hormones on the basolateral side of the gut barrier to evoke physiological responses (Gribble and Reimann, 2016). Some sensory epithelial cells, such as serotonin-secreting enterochromaffin cells (Bellono et al., 2017) and GLP-1-secreting L-cells (Bohórquez et al., 2015) form direct neural connections with afferent and efferent nerve fibers, meaning they are well equipped to translate luminal signals across an intact gut barrier to the host nervous system. In this study, we have investigated the potential of GLP-1 as a cross-barrier signaling molecule with stimulatory actions both on colonic afferents signaling to the CNS and locally, on submucosal neurons. The neurostimulatory actions of the bacterial metabolite, indole and GLP-1-secreting $L$. paracasei from the luminal side of the colon have been observed. Moreover, we have noted the need for an intact epithelium.
Combined with the role of neuronal GLP-1R activation, our data implicates L-cells as cellular transducers that couple microbial signaling molecules with activation of the host peripheral nervous system.

Acute exposure to indole stimulated basolateral secretion of GLP-1 from rat colonic tissue, which is likely to be mediated through direct activation of L-cells by indole (Chimerel et al., 2014) but could also be through indirect mechanisms. Indeed, indole can modify epithelial cells and tight junction proteins (Bansal et al., 2010). Consistent with the importance of the vagus in informing the CNS about changes in the gut microbiome (Bercik et al., 2011; Bravo et al., 2011; Riley et al., 2013), electrophysiological studies demonstrated that application of indole to the mucosa, but not directly onto exposed intrinsic or extrinsic neurons, resulted in GLP-1R-dependent activation of vagal afferents. In terms of gut-brain axis wiring, most innervation of small intestinal epithelial cells is by submucosal neurons (Keast et al., 1984; Ekblad et al., 1987) and intrinsic primary afferent neurons may act as the starting point in gut-brain signaling (Perez-Burgos et al., 2014). Interestingly, longer exposure times suppress GLP-1 release (Chimerel et al., 2014), which may be important in gut-brain signaling regulation.

Mechanistically, inhibition of indole-evoked stimulation of vagal afferents in hemisected SMP tissue with tetrodotoxin indicates the role of action potentials in signal generation. However, when the epithelial layer was left intact, tetrodotoxin did not modify vagal activation by indole. This is consistent with nerve endings terminating below the epithelium and further implicates cells embedded in the epithelium in cross-barrier signaling. We also found that mucosally-applied Ex-4 and GLP1 -secreting $L$. paracasei evoked vagal firing in colonic tissue with an intact epithelium, which may be mediated through activation of GLP-1Rs on L-cells leading to basolateral secretion of GLP-1 and subsequent activation of vagal afferents (Bohórquez et al., 2015). Indeed, the effects of $L$. paracasei, which was applied to colonic sections with intact mucosa, were attenuated by the GLP-1R antagonist.

Application of indole to submucosal neurons, which lie in closest proximity to the mucosal layer and regulate absorptosecretory function in the gut, had no impact on neuronal calcium levels in the absence of the epithelium. However, in contrast to the indirect mechanism underlying indole-evoked activation of the vagus nerve, submucosal neurons in hemisected tissue preparations were not activated by indole either, although we acknowledge that carrying out these studies at room temperature may have had an impact on temperature-sensitive elements. Nonetheless, the mucosal application of indole did enhance both the amplitude and duration of Ex-4-evoked calcium responses. This change in intracellular calcium levels could reflect slow excitatory postsynaptic potentials, slow inhibitory postsynaptic potentials or inhibitory slow after hyperpolarization seen in intrinsic primary afferent neurons, which are all dependent upon changes in intracellular calcium. Further studies will be needed to specifically determine which neuronal subtypes are affected. GLP-1R expression was increased in submucosal ganglia, which given the brief timeframe is likely to be due to the trafficking of GLP-1Rs to the cell membrane (Jones et al., 
A
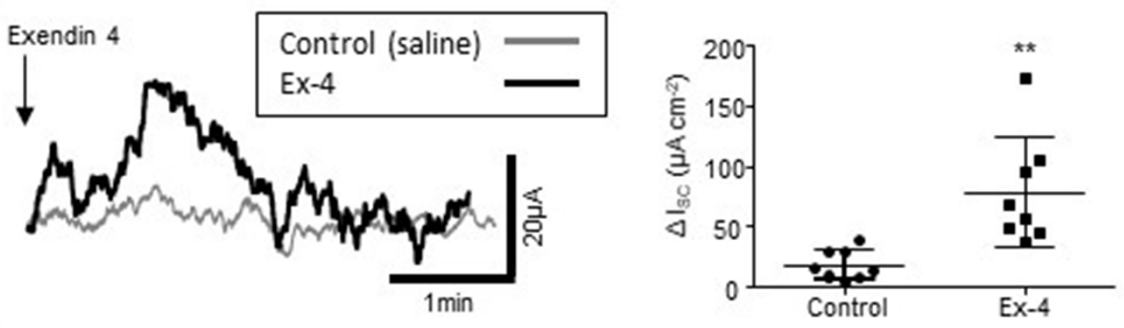

B

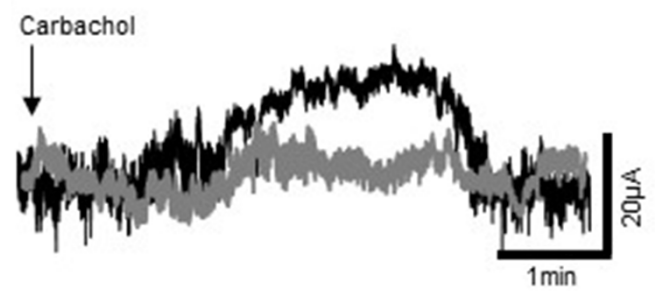

C
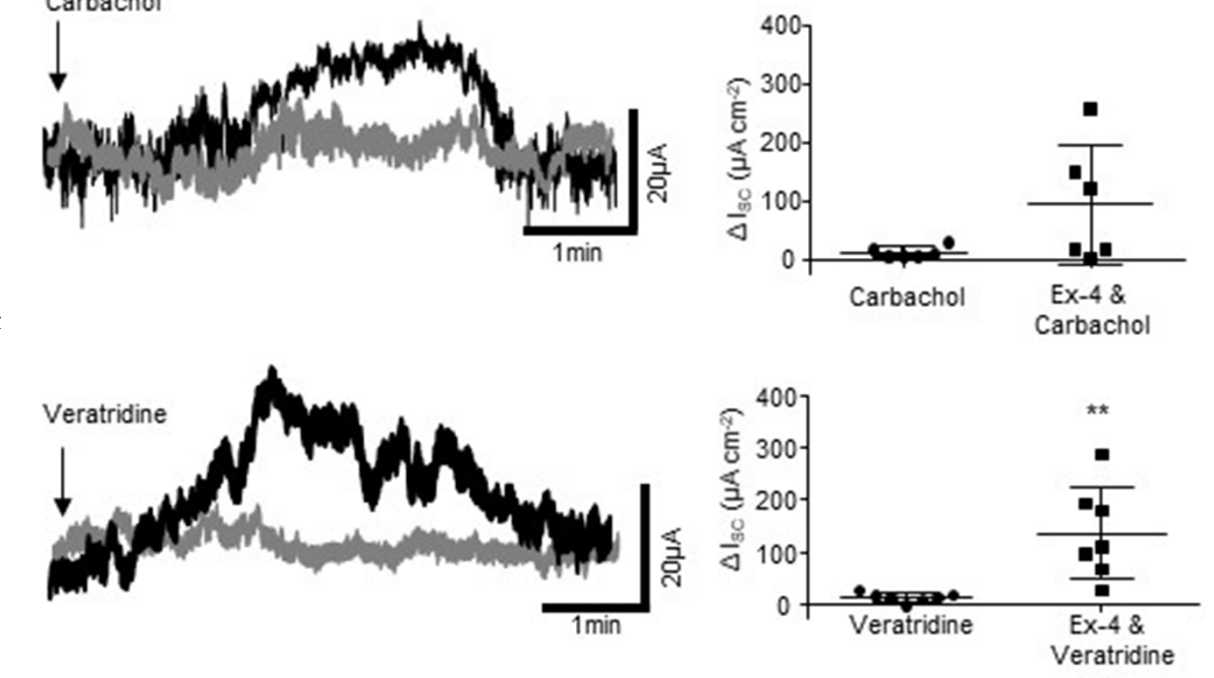

D
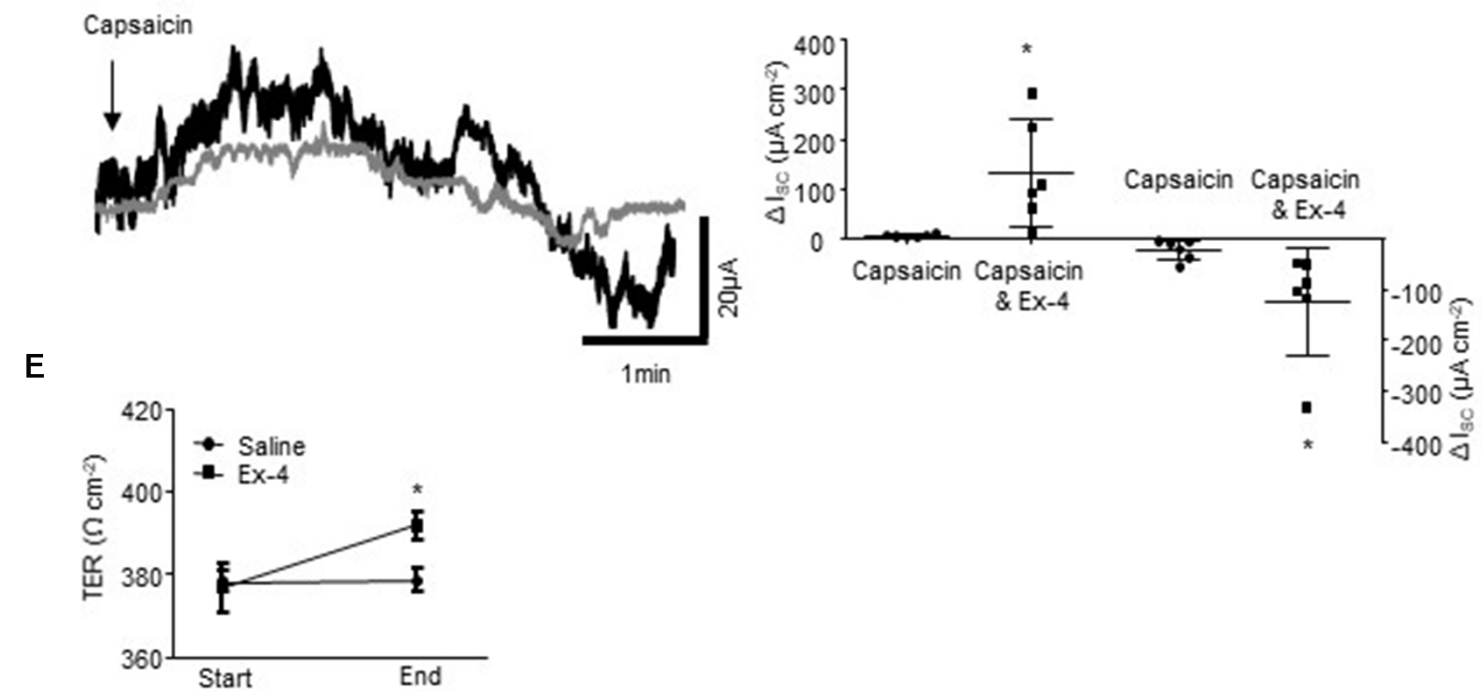

FIGURE 5 | Exendin-4 enhances colonic secretory currents. (A) The representative secretory traces from Ussing chamber studies and the associated scatter plots illustrate the secretory current evoked by the GLP-1R agonist, exendin 4 (Ex-4, $10 \mu \mathrm{M}, n=8)$. (B) Ex-4 does not modify the cholinergically-mediated secretory current (Isc) evoked by carbachol $(10 \mu \mathrm{M}, n=8)$ but enhances currents evoked by the (C) sodium channel agonist, veratridine (10 $\mu \mathrm{M}, n=8)$ and (D) the sensory nerve stimulant, capsaicin (1 $\mu \mathrm{M}, n=8$ ). (E) Ex-4 also increases transepithelial resistance (TER) throughout an experiment $\left(60-90\right.$ min). ${ }^{*} p<0.05,{ }^{\star *} p<0.01$.

2018). Comparable to the neurostimulatory effects of GLP-1 in the nodose ganglia (Kakei et al., 2002) and central neurons (Ma et al., 2007), Ex-4 stimulated a robust increase in $\left[\mathrm{Ca}^{2+}\right]_{\mathrm{i}}$ in submucosal neurons. This was dependent upon activation of
GLP-1Rs, which we and others (Kedees et al., 2013) have detected on submucosal neurons. Mucosal application of the secretory products of GLP-1-secreting L. paracasei similarly resulted in increased membrane expression of GLP-1R immunolabeling in 
submucosal ganglia, and evoked a GLP-1R-dependent calcium response. Although the ability of this engineered bacteria to modulate host physiology has been reported (Ryan et al., 2017), the mechanisms of action had not previously been elucidated. L-cells are reported to express a variety of receptors (Reimann et al., 2008; Tolhurst et al., 2012) but a study in mice indicated they do not express GLP-1Rs (Grigoryan et al., 2012). By contrast, we detected that some, but not all GLP-1immuno-labeled L-cells in rat colon expressed GLP-1Rs. Thus, GLP-1 secreted luminally by $L$. paracasei could stimulate the basolateral release of GLP-1 from L-cells in an autocrine manner, which in turn could activate intrinsic and extrinsic neurons. Pharmacological characterization of the Ex-4-evoked calcium response revealed that both, calcium release from intracellular stores and influx from extracellular sources, contributes to the response. The downstream signaling molecule, PI 3-kinase appears to play a role in Ex-4-induced activation of submucosal neurons and the STAT3 inhibitor attenuated, but did not abolish, the calcium response.

In terms of the known consequences of the neurostimulatory actions of the GLP-1 agonist on GI function, GLP-1 suppresses GI contractile activity (Schirra et al., 2006; Hellström et al., 2008), but less was known about the actions of GLP-1 on intestinal secretory activity (Baldassano et al., 2012). Bearing in mind potential confounders of ex vivo experiments, including a lack of circulation and the possible deterioration of tissue integrity, we demonstrated that Ex-4 induced a secretory current and enhanced secretion evoked by the voltage-sensitive $\mathrm{Na}^{+}$ channel agonist, veratridine and capsaicin, which is known to activate vagal afferents (Blackshaw et al., 2000); findings that are consistent with the stimulatory effects of Ex-4 on submucosal neurons. Similar to a previous study (Baldassano et al., 2012), we did not find that GLP-1 impacted on carbachol-evoked secretory responses. However, consistent with our finding that indole enhanced the amplitude and duration of Ex-4-evoked calcium responses in submucosal neurons, microbial-sensing by L-cells may result in enhancement of neurally-regulated colonic secretion. Indeed, acute application of indole prolongs GLP-1 secretion from L-cells (Chimerel et al., 2014). Ex-4 increased colonic TER, indicating that the gut was less permeable. This may reflect a local protective response to prevent penetration of the gut by bacterial products and contribute to the anti-inflammatory actions of Ex-4 in the intestine (Kissow et al., 2013).

\section{REFERENCES}

Anand, U., Yiangou, Y., Akbar, A., Quick, T., MacQuillan, A., Fox, M., et al. (2018). Glucagon-like peptide 1 receptor (GLP-1R) expression by nerve fibres in inflammatory bowel disease and functional effects in cultured neurons. PLoS One 13:e0198024. doi: 10.1371/journal.pone. 0198024

Baldassano, S., Wang, G. D., Mulè, F., and Wood, J. D. (2012). Glucagon-like peptide-1 modulates neurally-evoked mucosal chloride secretion in guinea pig small intestine in vitro. Am. J. Physiol. Gastrointest. Liver Physiol. 302, G352-G358. doi: 10.1152/ajpgi.00333.2011

Bansal, T., Alaniz, R. C., Wood, T. K., and Jayaraman, A. (2010). The bacterial signal indole increases epithelial-cell tight-junction resistance and attenuates

\section{CONCLUSION}

These studies implicate GLP-1 as a signaling molecule in cross-barrier communication between luminal bacteria and the host peripheral and central nervous systems. Strengths of our experimental design include the ability to record nerve fiber activity signaling to the CNS from the distal colon in real-time, although a lack of pre-planned power calculations for these studies is a design limitation. Understanding this mechanism may be important in appreciating the pathophysiology of several diseases, particularly those associated with microbial dysbiosis. Indeed, in diarrhea-predominant IBS, tryptophan, the precursor of indole is elevated (Christmas et al., 2010). Moreover, increased numbers of afferent neurons expressing GLP-1Rs have been reported in inflammatory bowel disease, which may be important in relaying visceral pain signals in the diseased gut (Anand et al., 2018). Thus, microbial sensing by L-cells and subsequent activation of colonic afferents and local enteric neurons by GLP-1 may play a key role in neural dysregulation of gut function.

\section{DATA AVAILABILITY STATEMENT}

The datasets generated for this study are available on request to the corresponding author.

\section{ETHICS STATEMENT}

The animal study was reviewed and approved by University College Cork Animal Experimentation Ethics Committee.

\section{AUTHOR CONTRIBUTIONS}

$\mathrm{MB}, \mathrm{RO}$ 'B, and EB: generated and analyzed data. RR and CS: provided probiotics. JB: tissue samples. DO'M: generated and analyzed data, supervised study, drafted the manuscript.

\section{FUNDING}

This work is supported by SFI-HRB-Wellcome research partnership (108228/Z/15/Z Seed Award), APC MI (12/RC/2273) and the Department of Physiology, University College Cork.

indicators of inflammation. Proc. Natl. Acad. Sci. U S A 107, 228-233. doi: 10.1073/pnas.0906112107

Bellono, N. W., Bayrer, J. R., Leitch, D. B., Castro, J., Zhang, C., O’Donnell, T. A., et al. (2017). Enterochromaffin cells are gut chemosensors that couple to sensory neural pathways. Cell 170, 185.e16-198.e16. doi: 10.1016/j.cell.2017. 05.034

Bercik, P., Park, A. J., Sinclair, D., Khoshdel, A., Lu, J., Huang, X., et al. (2011). The anxiolytic effect of Bifidobacterium longum NCC3001 involves vagal pathways for gut-brain communication. Neurogastroenterol. Motil. 23, 1132-1139. doi: 10.1111/j.1365-2982.2011.01796.x

Blackshaw, L. A., Page, A. J., and Partosoedarso, E. R. (2000). Acute effects of capsaicin on gastrointestinal vagal afferents. Neuroscience 96, 407-416. doi: 10.1016/s0306-4522(99)00547-3 
Bohórquez, D. V., Shahid, R. A., Erdmann, A., Kreger, A. M., Wang, Y., Calakos, N., et al. (2015). Neuroepithelial circuit formed by innervation of sensory enteroendocrine cells. J. Clin. Invest. 125, 782-786. doi: 10.1172/JCI78361

Bravo, J. A., Forsythe, P., Chew, M. V., Escaravage, E., Savignac, H. M., Dinan, T. G., et al. (2011). Ingestion of Lactobacillus strain regulates emotional behavior and central GABA receptor expression in a mouse via the vagus nerve. Proc. Natl. Acad. Sci. U S A 108, 16050-16055. doi: 10.1073/pnas. 1102999108

Buckley, M. M., and O'Malley, D. (2018). Development of an ex vivo method for multi-unit recording of microbiota-colonic-neural signaling in real time. Front. Neurosci. 12:112. doi: 10.3389/fnins.2018.00112

Cani, P. D., Joly, E., Horsmans, Y., and Delzenne, N. M. (2006). Oligofructose promotes satiety in healthy human: a pilot study. Eur. J. Clin. Nutr. 60, 567-572. doi: 10.1038/sj.ejcn. 1602350

Chimerel, C., Emery, E., Summers, D. K., Keyser, U., Gribble, F. M., and Reimann, F. (2014). Bacterial metabolite indole modulates incretin secretion from intestinal enteroendocrine L cells. Cell Rep. 9, 1202-1208. doi: 10.1016/j. celrep.2014.10.032

Christmas, D. M., Badawy, A. A., Hince, D., Davies, S. J., Probert, C., Creed, T., et al. (2010). Increased serum free tryptophan in patients with diarrheapredominant irritable bowel syndrome. Nutr. Res. 30, 678-688. doi: 10.1016/j. nutres.2010.09.009

Dinan, T. G., and Cryan, J. F. (2013). Melancholic microbes: a link between gut microbiota and depression? Neurogastroenterol. Motil. 25, 713-719. doi: $10.1111 / \mathrm{nmo.} 12198$

Dinan, T. G., and Cryan, J. F. (2017). Gut instincts: microbiota as a key regulator of brain development, ageing and neurodegeneration. J. Physiol. 595, 489-503. doi: 10.1113/JP273106

Duca, F. A., Sakar, Y., and Covasa, M. (2013). Combination of obesity and high-fat feeding diminishes sensitivity to GLP-1R agonist exendin-4. Diabetes 62, 2410-2415. doi: 10.2337/db12-1204

Ekblad, E., Winther, C., Ekman, R., Håkanson, R., and Sundler, F. (1987). Projections of peptide-containing neurons in rat small intestine. Neuroscience 20, 169-188. doi: 10.1016/0306-4522(87)90010-8

Gareau, M. G., Jury, J., and Perdue, M. H. (2007). Neonatal maternal separation of rat pups results in abnormal cholinergic regulation of epithelial permeability. Am. J. Physiol. Gastrointest. Liver Physiol. 293, G198-G203. doi: 10.1152/ajpgi. 00392.2006

Gibson, G. R., and Roberfroid, M. B. (1995). Dietary modulation of the human colonic microbiota: introducing the concept of prebiotics. J. Nutr. 125, 1401-1412. doi: 10.1093/jn/125.6.1401

Gribble, F. M., and Reimann, F. (2016). Enteroendocrine cells: chemosensors in the intestinal epithelium. Annu. Rev. Physiol. 78, 277-299. doi: 10.1146/annurev-physiol-021115-105439

Grigoryan, M., Kedees, M. H., Charron, M. J., Guz, Y., and Teitelman, G. (2012). Regulation of mouse intestinal L cell progenitors proliferation by the glucagon family of peptides. Endocrinology 153, 3076-3088. doi: 10.1210/en.20 $12-1120$

Hansen, C. F., Vrang, N., Sangild, P. T., and Jelsing, J. (2013). Novel insight into the distribution of L-cells in the rat intestinal tract. Am. J. Transl. Res. 5, 347-358.

Harada, K., Sada, S., Sakaguchi, H., Takizawa, M., Ishida, R., and Tsuboi, T. (2018). Bacterial metabolite S-equol modulates glucagon-like peptide-1 secretion from enteroendocrine L cell line GLUTag cells via actin polymerization. Biochem. Biophys. Res. Commun. 501, 1009-1015. doi: 10.1016/j.bbrc.2018. 05.100

Hellström, P. M., Naslund, E., Edholm, T., Schmidt, P. T., Kristensen, J., Theodorsson, E., et al. (2008). GLP-1 suppresses gastrointestinal motility and inhibits the migrating motor complex in healthy subjects and patients with irritable bowel syndrome. Neurogastroenterol. Motil. 20, 649-659. doi: 10.1111/j.1365-2982.2007.01079.x

Jaglin, M., Rhimi, M., Philippe, C., Pons, N., Bruneau, A., Goustard, B., et al. (2018). Indole, a signaling molecule produced by the gut microbiota, negatively impacts emotional behaviors in rats. Front. Neurosci. 12:216. doi: 10.3389/fnins. 2018.00216

Jones, B., Buenaventura, T., Kanda, N., Chabosseau, P., Owen, B. M., Scott, R., et al. (2018). Targeting GLP-1 receptor trafficking to improve agonist efficacy. Nat. Commun. 9:1602. doi: 10.1038/s41467-018-03941-2
Kaelberer, M. M., Buchanan, K. L., Klein, M. E., Barth, B. B., Montoya, M. M., Shen, X., et al. (2018). A gut-brain neural circuit for nutrient sensory transduction. Science 361:eaat5236. doi: 10.1126/science.aat5236

Kakei, M., Yada, T., Nakagawa, A., and Nakabayashi, H. (2002). Glucagonlike peptide- 1 evokes action potentials and increases cytosolic $\mathrm{Ca}^{2+}$ in rat nodose ganglion neurons. Auton. Neurosci. 102, 39-44. doi: 10.1016/s15660702(02)00182-0

Keast, J. R., Furness, J. B., and Costa, M. (1984). Origins of peptide and norepinephrine nerves in the mucosa of the guinea pig small intestine. Gastroenterology 86, 637-644. doi: 10.1016/s0016-5085(84)break80111-0

Kedees, M. H., Guz, Y., Grigoryan, M., and Teitelman, G. (2013). Functional activity of murine intestinal mucosal cells is regulated by the glucagon-like peptide-1 receptor. Peptides 48, 36-44. doi: 10.1016/j.peptides.2013.07.022

Kissow, H., Hartmann, B., Holst, J. J., and Poulsen, S. S. (2013). Glucagonlike peptide-1 as a treatment for chemotherapy-induced mucositis. Gut 62, 1724-1733. doi: 10.1136/gutjnl-2012-303280

Kuhre, R. E., Frost, C. R., Svendsen, B., and Holst, J. J. (2015). Molecular mechanisms of glucose-stimulated GLP-1 secretion from perfused rat small intestine. Diabetes 64, 370-382. doi: 10.2337/db14-0807

Ma, X., Bruning, J., and Ashcroft, F. M. (2007). Glucagon-like peptide 1 stimulates hypothalamic proopiomelanocortin neurons. J. Neurosci. 27, 7125-7129. doi: 10.1523/JNEUROSCI.1025-07.2007

Mao, Y. K., Kasper, D. L., Wang, B., Forsythe, P., Bienenstock, J., and Kunze, W. A. (2013). Bacteroides fragilis polysaccharide A is necessary and sufficient for acute activation of intestinal sensory neurons. Nat. Commun. 4:1465. doi: 10.1038/ncomms 2478

McVey Neufeld, K. A., Mao, Y. K., Bienenstock, J., Foster, J. A., and Kunze, W. A. (2013). The microbiome is essential for normal gut intrinsic primary afferent neuron excitability in the mouse. Neurogastroenterol. Motil. 25:183-e88. doi: $10.1111 /$ nmo. 12049

Nakagawa, A., Satake, H., Nakabayashi, H., Nishizawa, M., Furuya, K., Nakano, S., et al. (2004). Receptor gene expression of glucagon-like peptide-1, but not glucose-dependent insulinotropic polypeptide, in rat nodose ganglion cells. Auton. Neurosci. 110, 36-43. doi: 10.1016/j.autneu.2003.11.001

O’Brien, R., Buckley, M. M., Kelliher, A., and O'Malley, D. (2019). PI 3kinase- and ERK-MAPK-dependent mechanisms underlie Glucagon-Like Peptide-1-mediated activation of Sprague Dawley colonic myenteric neurons. Neurogastroenterol. Motil. 31:e13631. doi: 10.1111/nmo.13631

O'Malley, D., Dinan, T. G., and Cryan, J. F. (2011a). Altered expression and secretion of colonic interleukin- 6 in a stress-sensitive animal model of brain-gut axis dysfunction. J. Neuroimmunol. 235, 48-55. doi: 10.1016/j. jneuroim.2011.04.003

O’Malley, D., Liston, M., Hyland, N. P., Dinan, T. G., and Cryan, J. F. (2011b). Colonic soluble mediators from the maternal separation model of irritable bowel syndrome activate submucosal neurons via an interleukin-6-dependent mechanism. Am. J. Physiol. Gastrointest. Liver Physiol. 300, G241-G252. doi: 10.1152/ajpgi.00385.2010

Pérez-Berezo, T., Pujo, J., Martin, P., Le Faouder, P., Galano, J. M., Guy, A., et al. (2017). Identification of an analgesic lipopeptide produced by the probiotic Escherichia coli strain Nissle 1917. Nat. Commun. 8:1314. doi: 10.1038/s41467017-01403-9

Perez-Burgos, A., Mao, Y. K., Bienenstock, J., and Kunze, W. A. (2014). The gut-brain axis rewired: adding a functional vagal nicotinic "sensory synapse". FASEB J. 28, 3064-3074. doi: 10.1096/fj.13-245282

Perez-Burgos, A., Wang, B., Mao, Y. K., Mistry, B., McVey Neufeld, K. A., Bienenstock, J., et al. (2013). Psychoactive bacteria Lactobacillus rhamnosus (JB-1) elicits rapid frequency facilitation in vagal afferents. Am. J. Physiol. Gastrointest. Liver Physiol. 304, G211-G220. doi: 10.1152/ajpgi.00128.2012

Pusceddu, M. M., Barboza, M., Keogh, C. E., Schneider, M., Stokes, P., Sladek, J. A., et al. (2019). Nod-like receptors are critical for gut-brain axis signalling in mice. J. Physiol. 597, 5777-5797. doi: 10.1113/JP278640

Reimann, F., Habib, A. M., Tolhurst, G., Parker, H. E., Rogers, G. J., and Gribble, F. M. (2008). Glucose sensing in L cells: a primary cell study. Cell Metab. 8, 532-539. doi: 10.1016/j.cmet.2008.11.002

Richards, W., Hillsley, K., Eastwood, C., and Grundy, D. (1996). Sensitivity of vagal mucosal afferents to cholecystokinin and its role in afferent signal transduction in the rat. J. Physiol. 497, 473-481. doi: 10.1113/jphysiol.1996. sp021781 
Riley, T. P., Neal-McKinney, J. M., Buelow, D. R., Konkel, M. E., and Simasko, S. M. (2013). Capsaicin-sensitive vagal afferent neurons contribute to the detection of pathogenic bacterial colonization in the gut. J. Neuroimmunol. 257, 36-45. doi: 10.1016/j.jneuroim.2013.01.009

Ryan, P. M., Patterson, E., Kent, R. M., Stack, H., O’Connor, P. M., Murphy, K., et al. (2017). Recombinant incretin-secreting microbe improves metabolic dysfunction in high-fat diet fed rodents. Sci. Rep. 7:13523. doi: 10.1038/s41598017-14010-x

Schirra, J., Nicolaus, M., Roggel, R., Katschinski, M., Storr, M., Woerle, H. J., et al. (2006). Endogenous glucagon-like peptide 1 controls endocrine pancreatic secretion and antro-pyloro-duodenal motility in humans. Gut 55, 243-251. doi: 10.1136/gut.2004.059741

Stilling, R. M., Dinan, T. G., and Cryan, J. F. (2016). The brain's Geppettomicrobes as puppeteers of neural function and behaviour? J. Neurovirol. 22, 14-21. doi: 10.1007/s13365-015-0355-x

Sun, E. W., de Fontgalland, D., Rabbitt, P., Hollington, P., Sposato, L., Due, S. L., et al. (2017). Mechanisms controlling glucose-induced GLP-1 secretion in human small intestine. Diabetes 66, 2144-2149. doi: 10.2337/db 17-0058

Tolhurst, G., Heffron, H., Lam, Y. S., Parker, H. E., Habib, A. M., Diakogiannaki, E., et al. (2012). Short-chain fatty acids stimulate glucagon-like peptide-1 secretion via the G-protein-coupled receptor FFAR2. Diabetes 61, 364-371. doi: 10.2337/db11-1019

Wichmann, A., Allahyar, A., Greiner, T. U., Plovier, H., Lunden, G. Ö., Larsson, T., et al. (2013). Microbial modulation of energy availability in the colon regulates intestinal transit. Cell Host Microbe. 14, 582-590. doi: 10.1016/j.chom.2013.09. 012

Yano, J. M., Yu, K., Donaldson, G. P., Shastri, G. G., Ann, P., Ma, L., et al. (2015). Indigenous bacteria from the gut microbiota regulate host serotonin biosynthesis. Cell 161, 264-276. doi: 10.1016/j.cell.2015.02.047

Conflict of Interest: The authors declare that the research was conducted in the absence of any commercial or financial relationships that could be construed as a potential conflict of interest.

Copyright (C) 2020 Buckley, O'Brien, Brosnan, Ross, Stanton, Buckley and O'Malley. This is an open-access article distributed under the terms of the Creative Commons Attribution License (CC BY). The use, distribution or reproduction in other forums is permitted, provided the original author(s) and the copyright owner(s) are credited and that the original publication in this journal is cited, in accordance with accepted academic practice. No use, distribution or reproduction is permitted which does not comply with these terms. 